\title{
THE EXPERIMENTAL INFECTION OF CALVES WITH MYCOBACTERIUM ULCERANS
}

\author{
BY JEAN C. TOLHURST AND GLEN BUCKLE \\ Bacteriology Department, Alfred Hospital, Melbourne \\ AND N. A. M. WELLINGTON \\ Department of Agriculture, Victoria, Australia
}

\section{INTRODUCTION}

MacCallum, Tolhurst, Buckle \& Sissons (1948) reported the isolation of a previously undescribed acid-fast bacillus from skin lesions in man. The organism, Mycobacterium ulcerans, was characterized by its peculiar temperature requirements in that it would not grow in vitro at $37^{\circ} \mathrm{C}$. and by its capacity to produce oedema, ascites and ulceration of the skin in rats and mice.

The first series of patients found to be infected with Myco. ulcerans lived in the dairying districts of Bairnsdale and Colac in Victoria and, in considering the epidemiology of these infections, we felt we should investigate the possibility of cattle being the source of the infection. Traum $(1916,1919)$ reported the presence of unidentified acid-fast bacilli in skin lesions of cattle and it seemed possible that these organisms might be Myco. ulcerans.* A further reason for the investigation was related to the observations of Hastings, Beach \& Weber (1924) who found positive tuberculin reactions in cattle in which tuberculous or other lesions could not be demonstrated. This sensitization, which is now widely recognized, could possibly have been caused by infection with Myco. ulcerans.

It was decided, therefore, to undertake experimental inoculation of calves. MacCallum et al. (1948) had shown that the lesions in the natural infection in man and those produced experimentally in the rat occurred in the skin and subcutaneous tissues of areas where the temperatures were low as compared with the general body temperature and, therefore, the sites of inoculation selected for the calves were the limbs and the tail. It was not feasible to employ large numbers of animals in these experiments, but it was felt that the preliminary study of small numbers would probably indicate whether or not further experimentation was desirable.

\section{MATERIALS AND METHODS \\ Preparation of ulceranin}

In order to examine the possibility of tissue sensitization to Myco. ulcerans, it was first necessary to attempt the preparation from this organism of a substance which, like tuberculin, could be injected intradermally for the determination of sensitivity.

* When our experiments in calves were in progress, we had not seen Traum's disease. One of us (N.A.M.W.) has since discovered typical lesions in cattle in a number of different herds in Victoria. We have attempted, without success, to isolate Myco. ulcerans from some of these lesions. 
Four established laboratory strains of Myco. ulcerans, labelled respectively LH, KR, SF and RS, were inoculated separately into nutrient broth containing $10 \%$ horse serum and $1 \%$ glycerol. Each lot was incubated at $33^{\circ} \mathrm{C}$. and grown for periods of 4-7 months. Without concentration or further treatment, beyond centrifugation, the resultant fluids were used undiluted for the skin sensitivity tests. They were designated ulceranin with the appropriate subscription LH, KR, $\mathrm{SF}$, or RS according to the strain used for their preparation. Stored in the refrigerator at $+4^{\circ} \mathrm{C}$. these fluids proved to be relatively stable and one, at least, retained its original potency for more than two years.

\section{Skin tests in guinea-pigs}

Guinea-pigs were inoculated intraperitoneally with either saline suspensions of living cultures of Myco. ulcerans or with a suspension of the culture in paraffin oil. After an interval of about 2 months the animals were tested for sensitivity against both ulceranin (undiluted) and human tuberculin (diluted 1/100). The control preparation in each case was the uninoculated culture medium used for the manufacture of the test fluids. Each of the sensitized guinea-pigs was injected intradermally with $0 \cdot 1 \mathrm{ml}$. of the test fluid into the left flank and the same dose of the appropriate control fluid into a similar site on the opposite flank.

After $24 \mathrm{hr}$. the typical reaction appeared as an erythematous area of $1 \cdot 5-2 \cdot 0 \mathrm{~cm}$. in diameter. There was an inner blanched area of $1.0-1.5 \mathrm{~cm}$. with a livid centre. Detailed measurements for comparison and records were, however, not regularly made of the surface reactions but a careful record was kept of the intensity of each reaction by measuring with calipers the thickness of pinched-up skin at the site of the intradermal injection immediately before the test and again at the time of the maximum reaction. In the presence of a typical visible surface reaction there was an increase of skin thickness of $1.5-3.0 \mathrm{~mm}$; an increase of $1.5 \mathrm{~mm}$. or more was accepted as a positive reaction.

Guinea-pigs sensitized respectively with Myco. ulcerans strains LH, KR or PD reacted strongly to tests with ulceranin prepared from strains $L H, K R, S F$ and $\mathrm{RS}$; there were no apparent differences between the strains.

Distinct cross-reactions were obtained with diluted human tuberculin but in only one guinea-pig was the reaction equal in size to that given by ulceranin. At this stage of the work a systematic study of cross-reactivity in guinea-pigs was not undertaken. This has since been admirably performed by Fenner (1952) in beautifully planned experiments.

In our experiments in calves, the potency of the various preparations of ulceranin were always checked by testing them in sensitized guinea-pigs a few days before using them in the calves.

\section{Skin tests in calves}

In addition to ulceranin and human tuberculin, 'mammalian' tuberculin, avian tuberculin and (Expt. 1 and 2 only) johnin were used; these were all products of the Commonwealth Serum Laboratories, Australia. The mammalian tuberculin was a product designated 'Tuberculin Grown on Synthetic Medium' prepared 
with several strains of Myco. tuberculosis. It has been shown to be more specific than 'Old Tuberculin' and is in constant use for routine testing of cattle in Australia.

Intradermal tests were performed in the neck and/or the caudal fold or vulva, using $0.05 \mathrm{ml}$. volumes for each test; the results were recorded as measurements of skin thickness, together with a description of the nature of the reaction. When tests were performed in the neck an increase of $4 \mathrm{~mm}$. or more in skin thickness with a diffuse oedematous swelling was recorded as positive. When the site of injection was the caudal fold, a minimum positive reaction was recorded for an increase in skin thickness of $2 \mathrm{~mm}$. together with induration extending for $25 \mathrm{~mm}$. The same extent of induration with an increase of only $1 \mathrm{~mm}$. in skin thickness or induration $20 \mathrm{~mm}$. in length with an increase of skin thickness of $1.5 \mathrm{~mm}$. was recorded as doubtful. Induration extending for $15 \mathrm{~mm}$. with an increase in skin thickness of $1.5 \mathrm{~mm}$. was recorded as negative. The 'extent of induration' was measured with care but it was found difficult to define accurately. Only one test was done on the vulva (Table 3), and the increase of $3.5 \mathrm{~mm}$. in skin thickness was recorded as positive.

\section{RESULTS}

\section{Description}

First experiment

On 18 June 1948 a calf, kindly presented by Dr H. B. Rudduck, was inoculated by him with a fourth generation young culture of Myco. ulcerans, strain KR. One millilitre of the culture was inoculated subcutaneously in the mid-tail region, and $2 \mathrm{ml}$. of the culture was also injected subcutaneously above and behind the knee of the right foreleg.

When examined 2 weeks later both sites of injection showed nodules which appeared to be increasing in size. The tail was hard and shiny at the site of inoculation and the regional lymph nodes were enlarged.

Three months after inoculation (20 September 1948), the lesions had regressed. The tail was still slightly swollen but the knee was almost normal in appearance. The pre-scapular lymph nodes remained enlarged, the right node being described as the size of a walnut and the left as the size of an almond. Skin tests carried out at this time were negative with avian tuberculin and with johnin, but were positive with human tuberculin showing an increase of skin thickness from 10 to $16 \mathrm{~mm}$. with a prominent diffuse swelling.

Six months after inoculation (17 December 1948) the swelling on the calf's tail was reported to be about the size of a walnut; it was movable under the skin and fluctuant. The leg was not examined on this occasion.

Two months later (10 February 1949) the lesion on the tail was more pronounced, especially on the right side, and some of the joints above but more particularly those below the seat of infection, 'felt as though they contained fluid'. No comment was made on the leg but the pre-scapular lymph node of the right shoulder was found enlarged and appeared to be tender. The necessity to pasture the animal during 1949 on a farm remote from Melbourne and with poor yarding facilities made regular inspection impracticable. It remained, however, in apparent good 
health throughout the experiment. No discharge from any of the lesions was observed at the inspections but this may have occurred during the intervals.

\section{Post-mortem examination}

The animal was killed on 5 December 1949, about 18 months after inoculation. The tail appeared normal both superficially and on dissection. There was doubtful enlargement of the pre-crural and ischiatic lymph nodes and the right prescapular node contained necrotic material. No other abnormalities were found and the carcass was passed as healthy by a meat inspector.

Bacteriological examination of smears from the pre-crural and ischiatic nodes failed to show any acid-fast bacilli, but smears from the pre-scapular node showed a few acid-fast bacilli. Material from the latter was inoculated on to egg yolk agar slopes, but in spite of prolonged incubation at $33^{\circ} \mathrm{C}$. organisms were not cultivated. Two rats were inoculated intraperitoneally with the necrotic material; they were kept under observation for a period of 15 months, but no infection developed.

Histopathology. Sections were examined by Dr A. V. Jackson who reported:

The section shows several lymph nodes. All except one appear normal. In one the usual lymphoid follicular pattern is replaced by granulation tissue composed of foci of epithelioid cells with often a multi-nucleated giant cell of the Langhans' type. These foci are in some places, though not regularly, surrounded by a collar of small round cells. Scattered through the node are small masses of granular material which stain blue with haematoxylin and presumably contain calcium.

The histology is very similar to the picture in human tuberculosis, the only atypical elements being occasional groups and clumps of polymorphonuclear leucocytes. Comment: chronic lymphadenitis with some features also of acute inflammation. Histology compatible with infection of lymph nodes with Mycobacterium ulcerans.

\section{Description}

Second experiment

Two steer calves were tested intradermally in the neck with mammalian tuberculin on 8 April 1950, and with avian tuberculin, ulceranin and johnin on 20 June 1950. All the tests were negative in both animals.

On 29 June 1950, each calf was inoculated with a heavy suspension of a culture of Myco. ulcerans: (a) intradermally in the heel (the postero-medial aspect of the pastern), and (b) subcutaneously in the shank (the latero-posterior aspect of the distal end of the cannon bordering on the fetlock joint). Myco. ulcerans strain RT was used for the fawn steer and strain RS for the black steer.

Two days after inoculation no lesions were apparent, but 30 days later ( 31 July 1950) nodular lesions were observed on the heel of each animal and soft swellings were also present on the shank of each.

The animals were observed after $7,10,13$, and 18 weeks. Eighteen weeks after inoculation the observations were as follows: In the fawn steer there was a soft, circumscribed swelling about $1 \frac{1}{4} \times 1$ in. on the heel and a similar swelling about 1 in. in diameter on the shank. On the heel of the black steer the nodular lesion with a soft centre had subsided without discharging, leaving an indurated area of skin; on the shank there was a soft somewhat diffuse swelling about $2 \times 2 \frac{1}{2}$ in. extruding a bead of yellowish 'pus'. 
On 6 January 1951 ( 27 weeks) the lesion on the shank of the black steer was still discharging but smears failed to show any acid-fast bacilli.

Table 1. Second experiment. Intradermal tests on calves, 23 December 1950

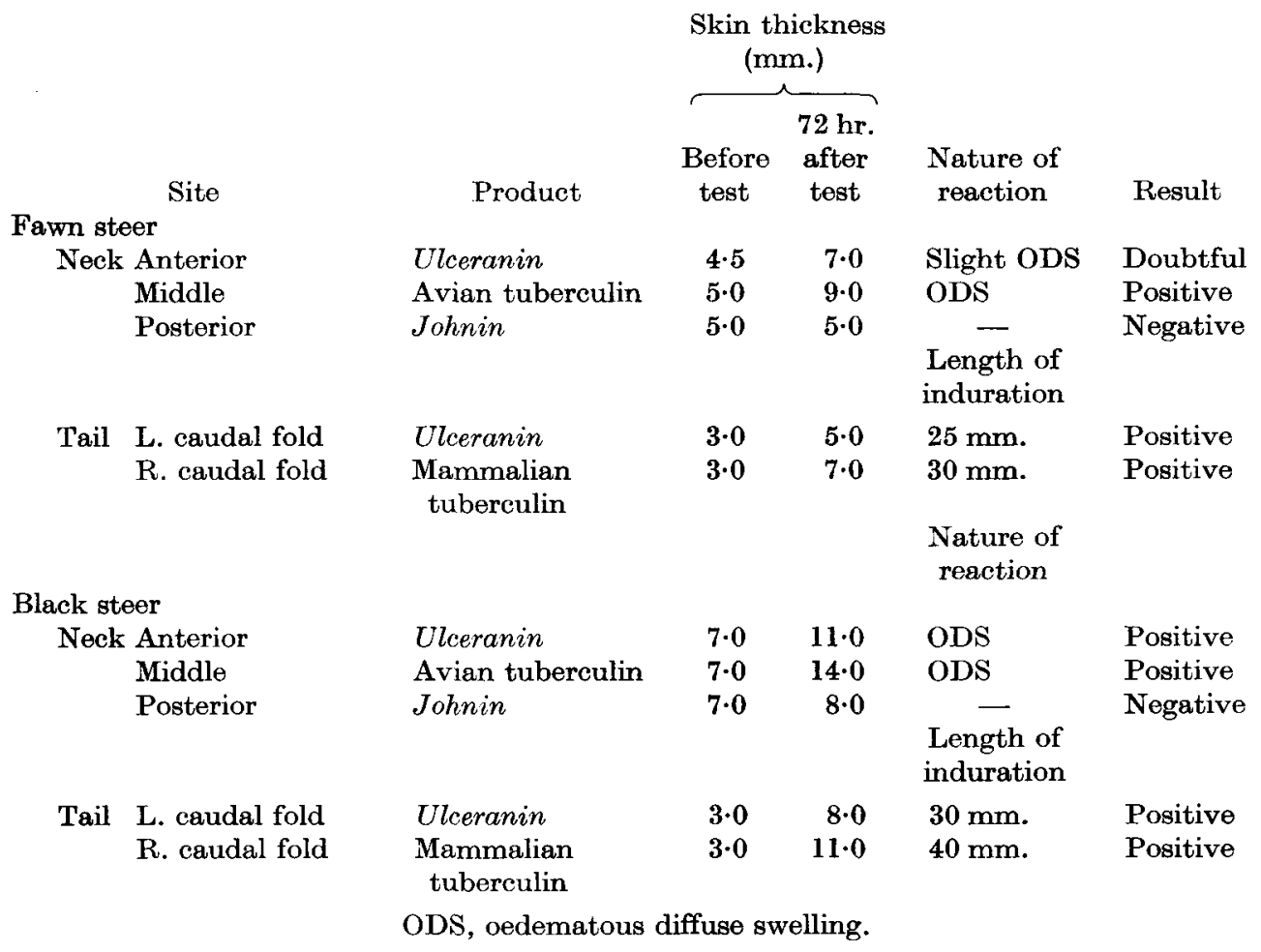

On 8 February 1951 (32 weeks) the lesion on the shank of the black steer was no longer discharging and was smaller in size and firmer; the nodule on the heel of this animal had almost completely disappeared, leaving only a diffuse induration. In the fawn steer, the lesion on the shank had become smaller, but was still circumscribed; the swelling on the heel was well pronounced and soft but was not discharging. Excision of this lower lesion for histological examination was considered but was not performed as we wished to follow the 'natural' course of the infection in these animals. The steers were inspected every 3-4 weeks until 27 October 1952, a period of 2 years and 4 months from the date of inoculation. There appeared to be no further development of the lesions during this period; indeed they retrogressed until only induration of the skin remained. The results of intradermal tests in the neck and the caudal fold performed on 23 December 1950 and again on 16 October 1952 are shown in Tables 1 and 2, respectively.

\section{Post-mortem examination}

The animals were destroyed on 27 October 1952. No lesions were found except induration of the skin; all lymph nodes appeared normal. Both carcasses were passed by a meat inspector as fit for human consumption. 
Table 2. Second experiment. Intradermal tests on calves, 16 October 1952

\begin{tabular}{|c|c|c|c|c|c|c|}
\hline & & & $\begin{array}{r}\text { Skin th } \\
(\mathbf{m}\end{array}$ & $\begin{array}{l}\text { iekness } \\
\text { n.) }\end{array}$ & & \\
\hline & Site & Product & $\begin{array}{c}\text { Before } \\
\text { test }\end{array}$ & $\begin{array}{c}72 \mathrm{hr} . \\
\text { after } \\
\text { test }\end{array}$ & $\begin{array}{l}\text { Nature of } \\
\text { reaction }\end{array}$ & Result \\
\hline Fawn st & eer & & & & & \\
\hline Neck & Anterior & Ulceranin & $5 \cdot 5$ & $6 \cdot 5$ & $\mathrm{~S}$ & Negative \\
\hline & Middle & Johnin & $5 \cdot 0$ & $7 \cdot 0$ & $\mathbf{S}$ & Negative \\
\hline & Posterior & Avian tuberculin & $5 \cdot 0$ & $7 \cdot 5$ & $\mathbf{S}$ & Doubtful \\
\hline & Base & $\begin{array}{l}\text { Mammalian } \\
\text { tuberculin }\end{array}$ & $4 \cdot 0$ & $8 \cdot 0$ & Slight ODS & Positive \\
\hline & & & & & $\begin{array}{l}\text { Length of } \\
\text { induration }\end{array}$ & \\
\hline Tail & L. caudal fold & Ulceranin & $3 \cdot 5$ & $4 \cdot 5$ & $15 \mathrm{~mm}$ & Negative \\
\hline & R. caudal fold & $\begin{array}{c}\text { Mammalian } \\
\text { tuberculin }\end{array}$ & $4 \cdot 0$ & $5 \cdot 5$ & $20 \mathrm{~mm}$ & Doubtful \\
\hline & & & & & $\begin{array}{l}\text { Nature of } \\
\text { reaction }\end{array}$ & \\
\hline Black st & eer & & & & & \\
\hline Neck & Anterior & Vlceranin & $6 \cdot 5$ & $7 \cdot 5$ & Slight $\mathbf{S}$ & Negative \\
\hline & Middle & Johnin & $6 \cdot 5$ & $8 \cdot 0$ & $\mathrm{~S}$ & Negative \\
\hline & Posterior & Avian tuberculin & $7 \cdot 0$ & $9 \cdot 0$ & $\mathbf{S}$ & Negative \\
\hline & Base & $\begin{array}{l}\text { Mammalian } \\
\text { tuberculin }\end{array}$ & $6 \cdot 5$ & $11 \cdot 0$ & Slight ODS & Positive \\
\hline & & & & & $\begin{array}{l}\text { Length of } \\
\text { induration }\end{array}$ & \\
\hline Tail & L. caudal fold & Ulceranin & $4 \cdot 5$ & $6 \cdot 0$ & $20 \mathrm{~mm}$. & Doubtful \\
\hline & R. caudal fold & $\begin{array}{c}\text { Mammalian } \\
\text { tuberculin }\end{array}$ & $4 \cdot 5$ & $7 \cdot 0$ & $25 \mathrm{~mm}$. & Positive \\
\hline
\end{tabular}

S, swelling; ODS, oedematous diffuse swelling.

Histopathology. Sections were examined by Dr A. V. Jackson who reported:

The four specimens of skin and subcutaneous tissue show some old scarring with scattered lymphocytes in the dermis. The appearances are consistent with old, resolved inflammation. There is no evidence now of any active pathology.

\section{Description}

\section{Third experiment}

On 6 January 1953 two heifer calves and a steer were purchased. They were kept segregated from other cattle for 6 weeks and then tested with ulceranin, mammalian tuberculin and avian tuberculin; there were no positive reactions.

On 6 March 1953 the animals were inoculated with a heavy saline suspension of Myco. ulcerans as follows:

No. 1 (heifer): (a) $1 \mathrm{ml}$. intradermally into the heel; (b) $2 \mathrm{ml}$. subcutaneously in the shank of the same leg.

No. 2 (steer): (a) $2 \mathrm{ml}$. subcutaneously into the tail, $1 \frac{1}{4}$ in. from the tip.

No. 3 (heifer): (a) $5 \mathrm{ml}$. into the jugular vein. 


\section{Development of lesions}

The development of lesions may be summarized thus:

Calf no. 1 (heifer). Three weeks after the intradermal inoculation into the heel there was a firm circumscribed swelling which reached a maximum of about $15 \mathrm{~mm}$. at the end of 5 weeks and remained the same until the animal was slaughtered 17 weeks after inoculation. The lesion on the shank at 3 weeks after inoculation was a fluctuant circumscribed swelling which increased to a maximum size of $38 \times 25 \mathrm{~mm}$. by the twelfth week and finally discharged a bead of pus at the end of 15 weeks. The right pre-scapular lymph node was found to be enlarged at the fifth week.

Calf no. 2 (steer). At the site of the inoculation in the tail there was a slight swelling at the end of 3 weeks, but this did not increase in size and at 8 weeks after inoculation a scab had formed.

Calf no. 3 (heifer). During the whole 4 months of the experiment no lesions were observed in this inoculated calf.

Intradermal tests were performed on all three calves on 29 June 1953 (16 weeks) and the readings made $72 \mathrm{hr}$. later are shown in Table 3.

\section{Post-mortem examination}

Calves nos. 1 and 2 were slaughtered on 2 July 1953, 17 weeks after inoculation. Apart from the lesions described above, no abnormalities were found. The right pre-scapular lymph node in calf no. 1 measured $70 \times 25 \mathrm{~mm}$.

Calf no. 3 was slaughtered on 16 July 1953 and no macroscopical lesions were found.

Bacteriology. Cultures were made from material obtained from the discharging lesion in calf no. 1 and from the right pre-scapular lymph node of the same animal, but no growth was obtained. Rats inoculated with some of the 'pus' failed to develop lesions.

The lesions in the tail of calf no. 2 showed many more acid-fast bacilli than those on the shank of calf no. 1 ; it is regrettable that cultures were not made.

Histopathology. Sections were examined by Dr A. V. Jackson who reported:

Calf no. $1(a)$, heel. The epidermis appears normal. About half of the dermis is replaced by numerous cellular foci, roughly circular on cross-section. They vary in diameter from 1 to $4 \mathrm{~mm}$. All the larger foci have necrotic and granular centres. This necrotic material resembles the 'caseation' of tuberculosis. Around these necrotic centres there is a ring of large cells with abundant cytoplasm resembling the epithelioid cells of tuberculosis. Around this zone and to some extent mingling with the epithelioid cells are small round cells. In some places these are scanty, in others plentiful. No giant cells or acid-fast bacilli can be seen.

Calf no. I (b), shank. The dermis is extensively involved by an inflammatory process which shows many polymorphs and appears more 'acute' than the smaller lesion in the heel. However, there are also epithelioid cells and a few giant cells in the background of the process so that it appears to be 'acute-on-chronic'. A few acid-fast bacilli are present.

Calf no. 1 (c). Right pre-scapular lymph node-no lesions can be found.

Calf no. 2, tail. Section shows several foci with central caseation and peripheral arrangement of epithelioid cells and small round cells and a few giant cells. This appears to be chronic inflammation resembling tuberculosis. A moderate number of acid-fast bacilli is present.

Calf no. 3. Sections of liver, lung, spleen, kidney and lymph nodes have been examined and no evidence of infection can be found. 
Table 3. Third experiment. Intradermal tests on calves, 29 June 1953

\begin{tabular}{|c|c|c|c|c|c|c|}
\hline & & & Skin th & $\begin{array}{l}\text { ckness } \\
\text { n.) }\end{array}$ & & \\
\hline & Site & Product & $\begin{array}{c}\text { Before } \\
\text { test }\end{array}$ & $\begin{array}{l}72 \mathrm{hr} . \\
\text { after } \\
\text { test }\end{array}$ & $\begin{array}{l}\text { Nature of } \\
\text { reaction }\end{array}$ & Regult \\
\hline Calf no. & 1. & & & & & \\
\hline Neck & Anterior & $\begin{array}{l}\text { Mammalian } \\
\text { tuberculin }\end{array}$ & $4 \cdot 0$ & $9 \cdot 5$ & Slight ODS & Positive \\
\hline & Middle & Avian tuberculin & $4 \cdot 0$ & $7 \cdot 0$ & DS & Doubtful \\
\hline & Posterior & Ulceranin & $4 \cdot 0$ & $11 \cdot 5$ & Slight ODS & Positive \\
\hline & & & & & $\begin{array}{l}\text { Length of } \\
\text { induration }\end{array}$ & \\
\hline Tail & L. caudal fold & $\begin{array}{c}\text { Mammalian } \\
\text { tuberculin }\end{array}$ & $2 \cdot 0$ & $6 \cdot 0$ & $28 \mathrm{~mm}$ & Positive \\
\hline & R. caudal fold & Ulceranin & $2 \cdot 0$ & $7 \cdot 0$ & $27 \mathrm{~mm}$. & Positive \\
\hline Vulv & a R. lip & Ulceranin & $3 \cdot 0$ & 6.5 & $\begin{array}{l}\text { Nature of } \\
\text { reaction }\end{array}$ & Positive \\
\hline Calf no. & & & & & & \\
\hline Neck & Anterior & $\begin{array}{l}\text { Mammalian } \\
\text { tuberculin }\end{array}$ & $5 \cdot 0$ & $7 \cdot 0$ & DS & Negative \\
\hline & Middle & Avian tuberculin & $4 \cdot 0$ & $6 \cdot 0$ & DS & Negative \\
\hline & Posterior & Ulceranin & $4 \cdot 0$ & $9 \cdot 0$ & Slight ODS & Positive \\
\hline & & & & & $\begin{array}{l}\text { Length of } \\
\text { induration }\end{array}$ & \\
\hline Tail & L. caudal fold & $\begin{array}{c}\text { Mammalian } \\
\text { tuberculin }\end{array}$ & $2 \cdot 0$ & $3 \cdot 0$ & $25 \mathrm{~mm}$ & Doubtful \\
\hline & R. caudal fold & Ulceranin & $2 \cdot 0$ & $7 \cdot 0$ & $30 \mathrm{~mm}$. & Positive \\
\hline
\end{tabular}

Calf no. 3

All tests negative

ODS, oedematous diffuse swelling. DS, Diffuse swelling.

\section{DISCUSSION}

The first experiment was of a preliminary nature; lesions developed at the sites of inoculation and post-mortem one of the regional lymph nodes was found to be affected. The tuberculin reaction was positive.

The second experiment allowed opportunities for more frequent observation. Lesions were discernible within 3 or 4 weeks and persisted for more than 32 weeks. One lesion was observed to be discharging 'pus' after 18 weeks and again after 27 weeks. Both calves showed conversion from negative to positive skin reactions with ulceranin and with mammalian and avian tuberculin.

This experiment was carried on for nearly $2 \frac{1}{2}$ years until complete healing of the lesions occurred. Histopathological examinations were then of little value. Just prior to slaughter, skin reactions were negative with ulceranin but still positive with tuberculin.

In the third experiment, the animals were killed after 17 weeks when the lesions, visible since 3 weeks, were well developed. The histopathology was similar to the 
reaction produced in man by Myco. ulcerans in which, although giant cells may occur, there is also a more acute polymorphonuclear response. Calves nos. 1 and 2 showed conversion of the skin reaction with both ulceranin and mammalian tuberculin. Conversion did not occur in the calf inoculated by the intravenous route but this is known to be a poor method of sensitization (Rich, 1946).

Although the number of inoculated animals is small, the experiments show that Myco. ulcerans can produce chronic lesions of the skin in calves which may discharge for many weeks. The lesions were, however, retrogressive and self-limiting. At a period of only 17 weeks after inoculation, acid-fast bacilli were scanty in the discharging lesion and failed either to grow in artificial culture or to infect rats. These observations are in contrast to the findings in rats experimentally infected with cultures, where enormous numbers of acid-fast bacilli are produced in progressive lesions in the tissues and are readily recovered in culture at $33^{\circ} \mathrm{C}$.

The lesions produced in calves with Myco. ulcerans by subcutaneous injection are of the order described following similar injections with human or with avian tubercle bacilli in which usually only a local lesion develops, accompanied by a lesion in the regional lymph node (Griffith, A. S. (1911); Griffith, F. (1911)).

The infection in cattle described by Traum $(1916,1919)$ may produce ulceration of the skin, subcutaneous nodules, or a form of lymphangitis with a chain of swellings along the lymphatic vessels. Although acid-fast bacilli are present in the lesions, these organisms have not been cultivated.

Intravenous inoculation of calves with avian tubercle bacilli may prove fatal within a few weeks (Griffith, F. (1911)). For this reason, a calf was inoculated intravenously with Myco. ulcerans. The animal did not develop lesions, but since the organism has a preference for low-temperature sites in the tissues (MacCallum et al. 1948), this negative result was not unexpected. Following intraperitoneal or intracerebral injections in rats, skin lesions sometimes develop and might conceivably occur in a proportion of calves inoculated intravenously.

Sensitization of calves to mammalian tuberculin following injections of $M y c o$. ulcerans is of interest, and would imply that if calves were naturally infected with Myco. ulcerans, a 'false positive' reaction to tuberculin would be found. Natural infection might occur occasionally but it seems unlikely, on the evidence presented, that cattle would be a reservoir of infection for other cattle and for man.

The epidemiology of Myco. ulcerans infection remains obscure. Bolliger, Forbes \& Kirkland (1950) showed that the common phalanger or possum (Trichosurus vulpecula) was highly susceptible. We examined thirty-one possums captured in the Bairnsdale area and found no specific lesions.

The occurrence of infections in man in the Belgian Congo (van Oye \& Ballion, 1950) and in Mexico (Lavalle Aguilar, Marquez Iturribarria \& Middlebrook, 1953) as well as in Australia, suggests, however, that the animal reservoir may be a species of widespread distribution. We have examined small numbers of wild rats and mice without success as yet. 


\section{SUMMARY}

Skin lesions with histopathology similar to that seen in lesions in man have been produced in calves by the experimental inoculation of cultures of Myco. ulcerans. Sensitization of infected calves to mammalian tuberculin as well as to ulceranin has been demonstrated.

It is considered unlikely that cattle are a reservoir of infection for man.

The expenses of this investigation were met by a research grant from the Board of Management, Alfred Hospital.

We are indebted to Dr A. V. Jackson, Director of Pathology, Alfred Hospital, for the reports on histopathology.

\section{REFERENCES}

Bolliger, A., Forbes, B. R. V. \& Kirkland, W. B. (1950). Transmission of a recently isolated mycobacterium to phalangers (Trichosurus vulpecula). Aust. J. Sci. $12,146$.

FenNer, F. (1952). Studies on Mycobacterium ulcerans. II. Cross-reactivity in guinea-pigs sensitized with Mycobacterium ulcerans and other mycobacteria. Aust. J. exp. Biol. 30, 11.

GRTFFITH, A. S. (1911). Investigation of viruses obtained from cases of human tuberculosis (other than lupus). Royal Commission on Tuberculosis (Human and Bovine), Final Report, part II, Appendix, 1, 29. H.M. Stationery Office, London.

GRIFFITH, F. (1911). Investigation of avian tubercle bacilli obtained from birds and swine. Royal Commission on Tuberculosis (Human and Bovine), Final Report, part II, Appendix, 4, 186. H.M. Stationery Office, London.

Hastings, E. G., Beach, B. A. \& Weber, C. W. (1924). No-lesion and skin-lesion tuberculinreacting cattle. J. Amer. vet. med. Assoc. 56 (New Series, 19), 36.

Lavalle Aguilar, P., Marquez Iturribarria, F. \& Middlebrook, G. (1953). Un caso de infeccion humana par Mycobacterium ulcerans en el hemisferio occidental nota previa. Internat. J. Leprosy, 21, 469.

MacCallum, P., Tolmurst, J. C., Buckle, G. \& Sissons, H. A. (1948). A new mycobacterial infection in man. J. Path. Bact. 60, 93.

Rich, A. R. (1946). The Pathogenesis of Tuberculosis, p. 354. Springfield, Illinois: Charles C. Thomas.

Traum, J. (1916). Case reports of lymphangitis in cattle caused by an acid-alcoholic fast organism. J. Amer. vet. med. Assoc. 49, 254.

Traum, J. (1919). Further report on lymphangitis in cattle caused by acid-alcohol fast organism. J. Amer. vet. med. Assoc. 55, 639.

van Oye, E. \& Batlion, M. (1950). Faudra-t-il tenir compte d'une nouvelle affection à bacilles acido-résistants en Afrique? Ann. Soc. Belg. Med. Trop. 30, 619.

(MS. received for publication 14 . vп. 58) 